\title{
Treatment outcomes of postoperative mediastinitis in cardiac surgery; negative pressure wound therapy versus conventional treatment
}

\author{
Hayati Deniz, Gokhan Gokaslan, Yavuz Arslanoglu, Ozerdem Ozcaliskan, Gokalp Guzel, Alptekin Yasim \\ and Hasim Ustunsoy
}

\begin{abstract}
Background: The aim of the present study is to compare negative pressure wound therapy versus conventional treatment outcomes at postoperative mediastinitis after cardiac surgery.

Methods: Between January 2000 and December 2011, after 9972 sternotomies, postoperative mediastinitis was diagnosed in 90 patients. The treatment modalities divided the patients into two groups: group 1 patients $(n=47)$ were initially treated with the negative pressure wound therapy and group 2 patients $(n=43)$ were underwent conventional treatment protocols. The outcomes were investigated with Kaplan-Meier method, log-rank test, Student's test and Fisher's exact test.

Results: The 90-days mortality was found significantly lower in the negative pressure wound group than in the conventionally treated group. Overall survival was significantly better in the negative pressure wound group than in the conventionally treated group.

Conclusion: Negative pressure wound therapy is safe and reliable option in mediastinitis after cardiac surgery, with excellent survival and low failure rate when compared with conventional treatments.
\end{abstract}

Keywords: Cardiac surgery, Sternal wound infection, Negative pressure wound therapy

\section{Background}

Infection of the sternotomy wound is a potentially devastating and sometimes lethal complication following cardiac surgery. Although the incidence of postcardiotomy mediastinitis rate has been variously reported as between 0.8 and $5.0 \%$, the mortality rate varies between $19 \%$ and $29 \%$ in different series of adult cardiac surgical patients [1-5]. Established treatment may involve a combination of debridement, packing, delayed closure, plastic reconstruction, re-wiring and irrigation together with antibiotherapy dependent on the severity of infection. However, such treatments can be complex, invasive and prolong the hospitalization particularly when the primary method fails. These conventional wound healing techniques may be a combination of

\footnotetext{
* Correspondence: hayatideniz@gmail.com

Gaziantep University Medical Faculty, Department of Cardiovascular Surgery, 27310, Sehitkamil, Gaziantep, Turkey
}

\section{() BioMed Central}

(c) 2012 Deniz et al.; licensee BioMed Central Ltd. This is an Open Access article distributed under the terms of the Creative Commons Attribution License (http://creativecommons.org/licenses/by/2.0), which permits unrestricted use, distribution, and reproduction in any medium, provided the original work is properly cited. different procedures, but there is still a lack of consensus for the optimal surgical management. Conventional treatment has disadvantages such as destabilization of the sternum, prolonged immobilization and concomitant infections, that may complicate this fatal treatment period [2-4]. Application of negative pressure by controlled suction through a porous dressing has emerged as a simple and effective treatment for a wide spectrum of wounds [6]. Several studies have been reported with promising results with the use of vacuum-assisted closure (VAC) therapy in poststernotomy mediastinitis that are also called deep sternal wound infections (DSWI) $[1,7-9]$.

The aim of the present study is to compare the clinical outcomes and survival in our 90 patients underwent negative pressure wound therapy (NPWT) or conventional treatment for mediastinitis after cardiac surgery. 


\section{Methods}

Between January 2000 and December 2011, 9972 sternotomies were performed in patients underwent cardiac surgical procedures at our cardiovascular surgery department. After a retrospective study design the study protocol was approved by the ethics committee for clinical research at our institution (Reference number: 22.11.2011/238). Only patients with mediastinitis those are consisting of sternum and presternal tissue infection were included in the present study. Patients undergoing thoracic aortic surgery extending to descending aorta, heart transplantation, congenital heart surgery and patients presenting signs of infection but with negative substernal tissue cultures or without mediastinitis were excluded from the study.

In 90 patients $(0,9 \%)$ postoperative mediastinitis was diagnosed, based on the guidelines of the US Centre for Disease Control and prevention [10]. Wound classification was defined according to the suggestions of El Oakley and Wright [11]. The diagnosis required at least one of the following criteria: (1) an organism was isolated from culture of mediastinal tissue or fluid; (2) evidence of mediastinitis was seen during operation; or (3) one of the following conditions, chest pain, sternal instability (detachment), or fever $\left(>38^{\circ} \mathrm{C}\right)$ was present and there was either purulent discharge from the mediastinum or an organism isolated from blood culture or drainage culture from the mediastinal area.

Patients' characteristics were analyzed retrospectively and according to the treatment modality, patients were divided into two groups: group 1 patients $(n=47)$ were initially treated with the NPWT and group 2 patients $(n=43)$ were underwent conventional treatment protocols. Choice of these protocols differed by time. Almost all patients with mediastinitis were treated by conventional protocols until 2003. By development of NPWT techniques; we increasingly used this protocol after 2003. By the time of initial diagnosis or suspicion of mediastinitis, bacteriological cultures of wound secretions were routinely taken from all patients and subsequently both protocols were continued until the consecutive bacteriologic cultures became negative. Afterwards surgery for primary closure of the sternum was performed.

\section{Conventional treatment}

Between January 2000 and December 2003, 43 consecutive patients were diagnosed as having poststernotomy mediastinitis. The technique of sternal excision and closure has been described previously [12]. The patients in this group underwent initial surgical revision with debridement of the presternal infected tissue and sternal edges where appropriate. This revision included removal of fibrins, necrotic tissue, and sternal wires. The surgical procedures which performed (rewiring, open dressings, closed irrigation or pectoral flaps) depended on the clinical condition of the patient and the surgeon's preference. Pectoral flaps were performed in cooperation with plastic surgeon.

Open dressings consisted of moist saline gauzes in the mediastinum for several days and were changed several times daily in combination with surgical revision. The procedure was concluded with a sterile drape covering the wound. When the wound became clean and there was a bed of fresh granulation tissue, the sternum was rewired.

Closed irrigation was initiated with one or two drains in the mediastinum. The sternum was closed in a standard manner with interrupted steel wires. The wound was also irrigated with normal saline solution, until the infection was considered under control. The drainage tubes were removed in the ward several hours after irrigation had ceased.

\section{Vacuum-assisted treatment}

Between May 2003 and December 2011, 47 consecutive patients with poststernotomy mediastinitis underwent NPWT. The patients in this group underwent initial surgical revision with removal of all sternal wires. The treatment modality was performed using the KCI system (KCI, San Antonio, Texas), with a vacuum pressure between $75 \mathrm{~mm}$ and $125 \mathrm{mmHG}$ according to the method described before [13].

This wound-healing technique is based on application local negative pressure to a wound. this is achieved by placing polyurethane foam with an open pore structure of $400-600 \mu \mathrm{m}$ in the wound. One end of a noncollapsible tube is then connected to the foam and the other end is connected to a vacuum-source in a closed system via connected to a fluid container. The foam and the entire wound are covered with an adhesive drape thus ensuring an air-tight system. Finally, a predetermined, intermittent, negative pressure is applied to the wound. Debridement and exchange of the sponge was performed every 48 to $72 \mathrm{~h}$ in the operation room. Substernal tissue cultures were collected for microbiological investigation and determination of the antibiotic resistance pattern. The wound was revised during VAC exchanges with sharp spoon and necrotic bone was removed if necessary, but extensive sternectomy was avoided.

All patients in both groups, prior to their primary operation received standardized preoperative antibiotic prophylaxis with two doses of intravenous cefuroxime $1.5 \mathrm{~g}$, on the day of operation and the first postoperative day. When the DSWI was diagnosed, the antibiotic therapy usually commenced with vancomysin intravenously and continued until the results of the wound cultures 
Table 1 Culture-verified deep sternal wound infection pathogens

\begin{tabular}{lccccc}
\hline Bacterial strains & \multicolumn{2}{c}{ VAC therapy } & & \multicolumn{2}{c}{ Conventional treatment } \\
\cline { 2 - 3 } \cline { 5 - 6 } & $\mathbf{n}$ & $\%$ & & $\mathbf{n}$ & $\%$ \\
\hline S.aureus & 14 & 29.8 & & 15 & 34.9 \\
E.coli & 4 & 8.5 & & 6 & 14 \\
K.pneumoniae & 1 & 2.1 & & - & 0 \\
S. epidermiditis & 9 & 19.1 & & 8 & 18.6 \\
Metisin resistance & 12 & 25.5 & & 10 & 23.3 \\
S. aureus & & & & & \\
Streptococcus & - & 0 & & 1 & 2.3 \\
E.coli+P.aeruginosa & 2 & 4.3 & & 2 & 4.7 \\
P.aeruginosa & 3 & 6.4 & & - & 0 \\
A.baumannii & 2 & 4.3 & & 1 & 2.3
\end{tabular}

The sum of percentages exceeds $100 \%$ because of rounding-off errors. $V A C=$ vacuum-assisted closure.

S. aureus $=$ Stafhylococcus aures; $E$. coli $=$ Escherichia coli; $K$. pneumoniae = Klebsiella pneumoniae; S. epidermiditis $=$ Stafhylococcus epidermiditis; E.coli $=$ Escherichia coli; P. auroginosa = Pseudomonas aeruginosa; $A$. baumannii $=$ Acinetobacter baumannii.

became available. The entire panorama of pathogens is presented in Table 1. Thereafter, the antibiotic therapy was adjusted according to bacterial sensitivity and strain. The antibiotic regimen was similar in both groups.

The preoperative variables, including the EuroSCORE [14], were collected from the department's database (Table 2). EuroSCORE was used to assess the grade of surgical complexity and preoperative status. In addition, risk factors considered relevant to poor wound healing and enhanced risk for sternal detachment, such as diabetes mellitus, obesity, low left ventricular ejection fraction (LVEF), chronic obstructive pulmonary disease (COPD), elderly age, renal failure, emergency surgery, re-do surgery, re-exploration, post perfusion syndrome, prolonged mechanical ventilation, prolonged intensive care unit (ICU) stay, prolonged use of inotropic drugs and immunosuppression therapy $[3,4,9,14,15]$, were collected from patients' medical records.

\section{Statistical analysis}

During the assessment of the study data, we investigated the distribution of categorical measurements according to the frequency and percentages, while we described our numerical parameters with mean and standard deviations. The survival functions for the conventional treatment group and the NPWT group were calculated using the Kaplan-Meier method. The nonparametric survival functions were then compared using the log-rank test. The two-sample Student's test was used to evaluate continuous variables. For categorical variables, Fisher's exact test was applied. The results were evaluated at a significance level of $\mathrm{p}<0.05$. NCSS (Number Cruncher Statistical System), 2007\&PASS (Power Analysis and
Sample Size), 2008 Statistical Software (Utah, USA) were used for statistical analysis.

\section{Results}

Mean age of patients was $62.86 \pm 11.6$ and 57 (63.3\%) of them were female and 33 (36.7\%) of them were male. Primary surgery among the 90 patients presenting with DSWI; 54 (60\%) had undergone coronary artery bypass revascularization, 29 (32.2\%) isolated valvular procedure and $7(7.8 \%)$ combined valvular and coronary bypass procedures. Demographic data and clinical characteristics of the patients are presented in Table 2. These patients were counted from 9972 sternotomies whom underwent a cardiovascular surgery. The incidence of mediastinitis was found $0.9 \%$, for our 11 years cardiac surgery experience.

The total 90 -days mortality was $15,6 \%$ (14 patients). The 90-days mortality was found significantly lower in the NPWT group than in the conventionally treated group (8.5\%, 4 patient versus 23.2\%, 10 patients; $p<0.05)$. The cause of all deaths in each group was multiorgan failure caused by severe sepsis. Treatment failure was observed in NPWT and conventional treatment groups $2.1 \%$ and $4.7 \%$ respectively. These patients were classified as El Oakley class type IV A and type IV B (Table 3 ) and unfortunately lost in first 45 postoperative day.

All patients in group 1 underwent sternal rewiring without flap surgery, after 3 consecutive bacteriologic cultures from substernal tissue became negative. In the conventional treatment group pectoral flap surgery was performed in $6.9 \%$ (3 patients).

Bacteriologic cultures showed the presence of staphylococi in the majority of patients. And the leading pathogenic organism was S.aureus for each group. The following organism was metisilin resistance S.aures. There was no significant difference between groups when compared the rate of polymicrobial infections (Table 3).

The preoperative variables, including the EuroSCORE and the risk factors relevant to poor wound healing were compared (Table 2); Patients from group 1 $(67.96 \pm 10.47$ years $)$ were significantly older than group 2 (57.3 \pm 14.7 years, $p<0.05$; Table 2$)$. Elderly patients those over 65 years old were more frequent in group 1 than in group 2 , with a statistically significance $(p<0.05$; Table 2). Patients with BMI over 30 were significantly more in group $1(70.2 \%)$ than in group 2 (51.2; $p<0.05$; Table 2). Female frequency was further in group 1 $(74.7 \%)$ than in group $2(51.2, p<0.05$; Table 2$)$ with a statistically significance. There were no significant difference between groups in terms of other risk factors such as diabetes mellitus, low left ventricular ejection fraction (LVEF), chronic obstructive pulmonary disease (COPD), 
Table 2 Patients characteristics

\begin{tabular}{|c|c|c|c|c|c|}
\hline \multirow[t]{2}{*}{ Variable } & \multicolumn{2}{|c|}{ VAC therapy } & \multicolumn{2}{|c|}{ Conventional treatment } & \multirow[t]{2}{*}{$p$ value } \\
\hline & n & $\%$ & n & $\%$ & \\
\hline Number of patients & 47 & 52.2 & 43 & 47.8 & \\
\hline \multicolumn{6}{|l|}{ Sex } \\
\hline Male & 12 & 25.3 & 21 & 48.8 & $0.003^{* *}$ \\
\hline Female & 35 & 74.7 & 22 & 51.2 & $0.003^{* *}$ \\
\hline \multicolumn{6}{|l|}{ Surgical procedure } \\
\hline Isolated or combined CABG procedure & 32 & 68.1 & 29 & 67.4 & 0.262 \\
\hline Isolated valvular procedure & 15 & 31.9 & 14 & 32.6 & 0.302 \\
\hline Diabetes mellitus & 15 & 31.9 & 14 & 32.6 & 0.255 \\
\hline Obesity (BMI $\geq 30$ ) & 33 & 70.2 & 22 & 51.2 & $0.043^{* *}$ \\
\hline LVEF $\leq 0.30$ & 10 & 21.3 & 11 & 25.6 & 0.116 \\
\hline NYHA Class III-IV & 19 & 40.4 & 13 & 30.2 & 0.078 \\
\hline COPD & 9 & 19.1 & 8 & 18.6 & 0.298 \\
\hline Age $>65$ years & 26 & 55.3 & 13 & 30.2 & $0.004^{* *}$ \\
\hline Renal failure* & 2 & 4.3 & 1 & 2.3 & 0.065 \\
\hline Emergency surgery & 7 & 14.9 & 5 & 11.6 & 0.122 \\
\hline Re-do surgery & 4 & 8.5 & 3 & 6.9 & 0.190 \\
\hline Re-exploration & 9 & 19.1 & 5 & 11.6 & 0.053 \\
\hline Post perfusion syndrome & 13 & 27.7 & 10 & 23.2 & 0.272 \\
\hline Prolonged mechanical ventilation & 21 & 44.7 & 16 & 37.2 & 0.185 \\
\hline ICU stay $>2$ days & 19 & 40.4 & 20 & 46.5 & 0.197 \\
\hline Prolonged use of inotropic drugs & 20 & 42.6 & 17 & 39.5 & 0.177 \\
\hline \multirow[t]{2}{*}{ Immunosuppression } & 1 & 2.1 & 1 & 2.3 & 0.344 \\
\hline & Mean & SD & Mean & SD & \\
\hline CPB time (minutes) & 119 & 33.18 & 123.1 & 28.28 & 0.150 \\
\hline X-clamp time (minutes) & 98.2 & 28.08 & 99.3 & 14.14 & 0.313 \\
\hline Age (y) & 67.96 & 10.47 & 57.3 & 14.7 & $0.004^{* *}$ \\
\hline EuroSCORE & 7.5 & 3.4 & 5.0 & 2.6 & $<0.001^{* *}$ \\
\hline
\end{tabular}

*Serum creatinin $>1.3 \mathrm{mg} / \mathrm{dl}$.

$* *<0.05$ is the statistically significance value.

$V A C=$ Vacuum-assisted closure; $C A B G=$ Coronary artery bypass graft; $B M I=$ body mass index; $L V E F=$ left ventricular ejection fraction; $N Y H A=$ New York Heart Association; $C O P D=$ chronic obstructive pulmonary disease; $C P B=$ cardiopulmonary bypass.

The sum of percentages exceeds $100 \%$ because of rounding-off errors.

renal failure, emergency surgery, re-do surgery, reexploration, post perfusion syndrome, prolonged mechanical ventilation, prolonged intensive care unit (ICU) stay, prolonged use of inotropic drugs and immunosuppression therapy (Table 2).

Median hospital stay for VAC group and conventional group were $26 \pm 8,31 \pm 9$ respectively and whereas the treatment duration for the conventional treatment group was longer than the VAC group $18 \pm 9$ days, $24 \pm 10$ days respectively, without statistically significance.

There was no significant difference in recurrent sternal fistulas between group 1 (1 patient, (2.1\%)) and group 2 (2 patients, $(4.6 \%))$. The patients were readmitted in the second month of discharged period and the fistulas were debrided under general anesthesia. The fistulas were obliterated completely, without sternectomy in combination with antibiotic therapy.

Overall survival was significantly better in the VAC group $(\mathrm{p}<0.05)$ than in the conventionally treated group: $91.5 \% \pm 1.2 \% \quad(\mathrm{n}=43) \quad$ versus $76.7 \% \pm 1.0 \% \quad(\mathrm{n}=33)$ at 1 year, $89.3 \% \pm 2.3 \%(n=42)$ versus $74.4 \% \pm 3.0 \%(n=32)$ at second year and $87.2 \% \pm 2.4 \% \quad(\mathrm{n}=41) \quad$ versus $69.8 \% \pm 2.9 \%(\mathrm{n}=30)$ at fifth year respectively (Figure 1$)$. There were 2 late deaths in the VAC group and 3 late deaths in the conventionally treated group. None of the late deaths were related with ongoing infections in either group. 
Table 3 Poststernotomy mediastinitis classification

\begin{tabular}{lcccccc}
\hline El Oakley Class & \multicolumn{2}{c}{ VAC therapy } & & \multicolumn{2}{c}{ Conventional treatment } \\
\cline { 2 - 3 } \cline { 2 - 3 } \cline { 5 - 6 } & $\mathbf{n}$ & $\%$ & & $\mathbf{n}$ & $\%$ \\
\hline II & 5 & 10.6 & & 4 & 9.3 \\
IIIA & 2 & 4.3 & & 3 & 7 \\
IIIB & 17 & 36.1 & & 13 & 30.2 \\
IVA & 22 & 46.8 & & 21 & 49 \\
IVB & 1 & 2.1 & & 1 & 2.3 \\
V & - & 0 & & 1 & 2.3 \\
\hline
\end{tabular}

The sum of percentages exceeds $100 \%$ because of rounding-off errors. $V A C=$ vacuum-assisted closure.

\section{Discussion}

According to the literature, the incidence of poststernotomy mediastinitis has been variously reported as between 0.8 and $5.0 \%$ in different series of adult cardiac surgical patients $[1-5,16,17]$. Our findings correlate with those of guidelines of the US Centre for Disease Control and prevention [10] and a recent study using the El Oakley classification [11]. In this present study we found the incidence of poststernotomy mediastinitis at a rate of 0,9\%, at 9972 sternotomies.

DSWI was initially treated with surgical revision, with or without multiple open dressing changes that have been previously reported with high mortality rates and has major disadvantages: sternal instability which requires mechanical ventilation, prolonged immobilization that increases additional complications as pneumonia, thrombosis and muscular weakening [18]. After some unsatisfying procedures an established method was the use of vascularized soft tissue flaps [19-21]. When Jurkiewicz and colleagues published the first pectoral muscle flap, a lot of studies have been reported varying results with pectoral muscle flaps in poststernotomy mediastinitis [22,23]. Other studies advocate the technique using omentum flaps first described by Lee and coworkers for poststernotomy mediastinitis [24]. These soft tissue flaps has relatively low mortality rate according to some reports, but may be associated with flap-related morbidity [23,25].

VAC therapy is a novel wound healing method. With this method, several advantageous features of conventional treatment are combined. VAC treatment allows open drainage that continuously absorbs the exudate with simultaneous stabilization of the mediastinal cavity and isolation of the wound. This method stimulates granulation tissue formation in combination with increased blood flow in the adjacent tissue [26]. Furthermore, VAC therapy approximates the wound edges and provides a mass filling effect with low degree of surgical trauma [26].

In this study, we retrospectively compared the clinical outcome and survival in 90 patients undergoing VAC therapy or conventional treatment for DSWI after cardiac surgery.

The bacteriologic spectrum, identified in bacteriologic cultures was found similar to other studies with a majority of $S$ aures infection (56.7\%) and coagulase negative Staphylococcus (18.9\%) (Table 1) [27]. Blood cultures were positive in 19 patients (21.1\%) and were not predictive for the success rate of the treatment modality. There was also no significant difference in terms of

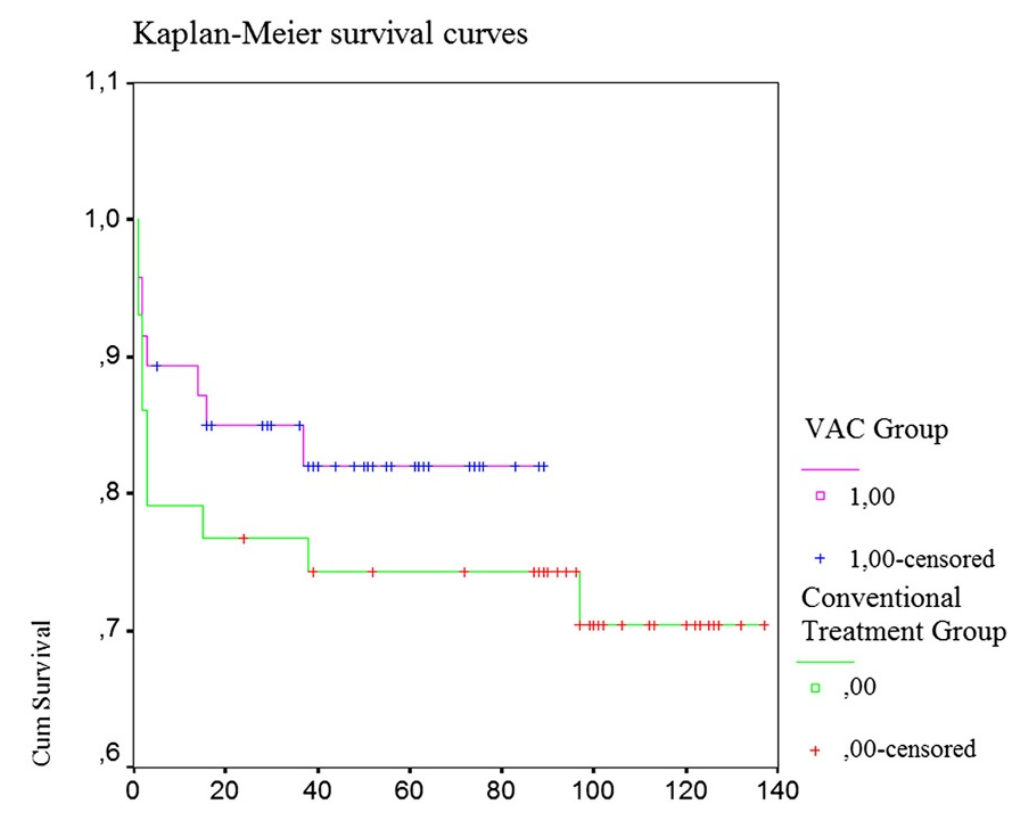

Figure 1 Kaplan-Meier survival curves. 
outcome based on organism in our study, which is consistent with the findings from Douville and colleagues [27]. In their study, vacuum-assisted treatment was not available, and patients underwent debridement, drainage and primary sternal reclosure or muscle flap. Overall mortality in their series was reported $12.6 \%$, however $6.3 \%$ of them were related with poststernotomy mediastinitis. These results are less than overall mortality of our study $(21,1 \%$ in our study, of which $15,5 \%$ was mediastinitis related) [27].

Catarino and coworkers performed an early, small, retrospectively study and demonstrated a significantly greater number of treatment failures with continuous irrigation compared with VAC therapy [28]. However in our study the number of failures to respond to the VAC treatment was present with a low rate in both of groups. The patients with failures to treatment modalities in both groups were classified as El Oakley class type IV A and type IV B (Table 3). The fistulas were obliterated completely, without sternectomy.

Previous studies have reported that mediastinitis is an independent risk factor with negative influence on longterm survival after coronary bypass graft surgery $[3,4,29]$. The reason for this negative prognostic effect is not fully understood, but a severe infection can lead other organ malperfusions such as the heart, kidneys and grafts. In our study we observed that VAC group has a significantly better early and long-term survival than the conventionally treated group (Figure 1).

Doos and coworker reported a study demonstrating a shorter length of stay and treatment period after VAC therapy. However Sjogren and coworkers did not found similar results with any significant difference in length of stay and treatment duration. But a new study by Simek and coworkers found a particular decrease in the length of hospital stay with statistical significans of $\mathrm{P}<0.05$ when compared with a conventional treatment method (simek). In our study we did not observe any significant difference in length of stay or treatment duration between VAC therapy and conventional treatment $[9,30,31]$.

\section{Conclusion}

Although the population became older, more obese, the increase in proportion of females and the EuroSCORE, during the last decade the incidence of mediastinitis after cardiac surgery did not change. However major changes occurred in number of patients at risk. Although risky patients was found higher in our study which were mostly included in the VAC group, the present study demonstrates that VAC therapy is safe and reliable option in DSWI, with excellent survival and low failure rate when compared with conventional treatments as like as in Assmann A and cowerkers study [32].

\section{Competing interest}

The authors declare that they have no competing interests.

\section{Authors' contributions}

$\mathrm{HD}$ and GG carried out the study design and drafted the manuscript, YA, OO and GG collected patients data, AY performed the statistical analysis, HU participated in the design of the study. All authors read and approved the final manuscript.

Received: 29 February 2012 Accepted: 16 June 2012

Published: 11 July 2012

\section{References}

1. Tang ATM, Ohri SK, Haw MP: Novel application of vacuum assisted closure tecnique to the treatment of sternotomy wound infection. Eur J Cardio-Thorac Surg 2000, 17:482-484.

2. Raudat CW, Pagel J, Woodhall D, Wojtanowski M, Van Bergen R: Early interventin and aggresive management of infected median sternotomy incision: a reviwe of 2242 open-heart procedures. Am Surg 1997, 63:238-241.

3. Milano CA, Kesler K, Archibald N, Sexton DJ, Jones RH: Mediastinitis after coronary artery bypass graft surgery. Circulation 1995, 92:2245-2251.

4. Lu JCY, Grayson AD, Jha P, Srinivasan AK, Fabri BM: Risk factors for sternal wound infection and mid-term survival follewing coronary artery bypass surgery. Eur J Cardiovasc Surg 2003, 23:943-949.

5. Gardlung B, Bitkover CY, Vaage J: Postoperative mediastinitis in cardiac surgery-microbiology and pathogenesis. Eur J Cardiovasc Surg 2002, 21:825-830

6. Argenta LC, Morykwas MJ: Vacuum-assisted closure: a new method for wound control and treatment: clinical experience. Ann Plast Surg 1997, 38:563-576.

7. Obdeijn MC, de Lange MY, Lichtendahl DH, de Boer WJ: Vacuum-assisted closure in treatment of poststernotomy mediastinitis. Ann Thorac Surg 1999, 68:2358-2360

8. Luckraz H, Murphy F, Bryant S, Charman S, Ritchie A: Vacuum-assisted closure as a treatment modality for infections after cardiac surgery. $J$ Thorac Cardiovasc Surg 2003, 125:301-305.

9. Sjögren J, Gustafsson R, Dobre M, Koul B, Ingemansson R, Algotsson L: Vacuum-assisted closure therapy in mediastinitis after heart transplantation. J Heart Lung Transplant 2004, 23:506-507.

10. Garner J, Jarvis WR, Emori GT, Horan TC, Huges J: CDC definitions for nosocomial infections 1988. Am J Infect Control 1988, 16:128-140.

11. El Oakley R, Wright J: Postoperative mediastinitis: clasification and management. Ann Thorac Surg 1996, 61:1030-1036.

12. Wettstein $R$, Erni $D$, Berdat $P$, Rothenfluh $D$, Banic A: Radical sternotomy and primary musculocutaneous flap reconstruction to control sternal osteitis. J Thorac Cardiovasc Surg 2002, 123:1185-1190.

13. Gustafsson Rl, Sjogren J, Ingemansson R: Deep sternal wound infection: a sternal sparing technique with vacuum-assisted closure therapy. Ann Thorac Surg 2003, 76:2048-2053.

14. Nashef SAM, Roques F, Michel P, et al: European system for cardiac operative risk evaluation (EuroSCORE). Eur J Cardiovasc Surg 1999, 16:9-13.

15. De Feo M, Renzulli A, Isomeno G, et al: Variables predicting adverse outcome in patients with deep sternal wound infection. Ann Thorac Surg 2001, 71:324-331.

16. Julian OC, Lopez-Belio M, Dye WS, Javid H, Grove WJ: Appraisal of progress in surgical therapy. Surgery 1957, 42:753-761.

17. Loop FD, Lytle BW, Cosgrove DM, et al: Sternal wound complications after isolated coronary artery bypass grafting: early and late mortality, morbidity and cost of care. Ann Thorac Surg 1990, 49:179-187.

18. Sarr MG, Gott VL, Townsend TR: Mediastinal infections after sternotomy. Ann Thorac Surg 1984, 38:415-423.

19. Bryant $L R$, Spencer FC, Trinkle TR: Treatment of median sternotomy infection by mediastinal irrigation with an antibiotic solution. Ann Thorac surg 1969, 169:914-920.

20. Rand RP, Cochran RP, Aziz S, et al: Prospective trial of catheter irrigation and muscle flaps for sternal wound infection. Ann Thorac Surg 1998, 65:1046-1049 
21. Grossi EA, Culliford AT, Krieger KH, et al: A survey of 77 major infectious complications of median sternotomy: arewiev of 7949 consecutive operative procedures. Ann Thorac Surg 1985, 40:214-223.

22. Jurkiewicz MJ, Bostwick J, Hester TR, Bishop JB, Craver J: Infected median sternotomy wound; successful treatment by muscle flaps. Ann Surg 1980, 191:738-744.

23. Jones G, Jurkiewicz MJ, Bostwick J, et al: Management of the infected median sternotomy wound with muscle flaps: the Emory 20 year experience. Ann Surg 1997, 225:766-776.

24. Lee $A B$, Schimert $G$, Shatkin $S$, et al: Total excision of the sternum and thtacic pedicle transposition of the greater omentum. Surgery 1976, 80:433-436.

25. Milano CA, Georgiade G, Mulbaier LH, et al: Comparison of omental and pectoral flaps for poststernotomy mediastinitis. Ann Thorac Surg 1999, 67:377-381.

26. Morykwas MJ, Argenta LC, Shelton-Brown EL, McGuirt W: Vacuum-assisted closure: a new method for wound control and treatment: animal studies and basic foundation. Ann Plast Surg 1997, 38:553-562.

27. Douville EC, Asaph JW, Dworkin RJ, et al: Sternal preservation: beter way to treat most sternal wound compications after cardiac surgery. Ann Thorac Surg 2004, 78:1659-1664.

28. Catarino PA, Chamberlain MH, Wright NC, et al: High-pressure suction drainage via a polyurethane foam in the management of poststernotomy mediastinitis. Ann Thorac Surg 2000, 70:1891-1895.

29. Braxton JH, Marrin CAS, McGrath PD, et al: Mediastinitis and long-term survival after coronary bypass graft surgery. Ann Thorac Surg 2000, 70:2004-2007.

30. Doss M, Martens S, Wood JP, Wolff JD, Basier C, Moritz A: Vacuum-assisted suction drainage versus conventional treatment in the management of poststernotomy osteomyelitis. Eur J Cardiovasc Surg 2002, 22:934-938.

31. Simek M, Hajek R, Fluger I, Molitor M, Grulichova J, Langova K, Tobbia P, Nemec $P$, Zalesak B, Lonsky V: Superiority of topical negative pressure over closed irrigation therapy of deep sternal wound infection in cardiac surgery. J Cardiovasc Surg (Torino) 2012, 53(1):113-120.

32. Assmann A, Boeken U, Feindt $P$, Schurr $P$, Akhyari $P$, Lichtenberg A: Vacuum-assisted wound closure is superior to primary rewiring in patients with deep sternal wound infection. Thorac Cardiovasc Surg 2011, 59(1):25-29. Epub 2011 Jan 17.

doi:10.1186/1749-8090-7-67

Cite this article as: Deniz et al:: Treatment outcomes of postoperative mediastinitis in cardiac surgery; negative pressure wound therapy versus conventional treatment. Journal of Cardiothoracic Surgery 2012 7:67.

\section{Submit your next manuscript to BioMed Central and take full advantage of:}

- Convenient online submission

- Thorough peer review

- No space constraints or color figure charges

- Immediate publication on acceptance

- Inclusion in PubMed, CAS, Scopus and Google Scholar

- Research which is freely available for redistribution 